\title{
The role of CCL21/CCR7 chemokine axis in breast cancer-induced lymphangiogenesis
}

\author{
Elena Tutunea-Fatan ${ }^{1}$, Mousumi Majumder ${ }^{1}$, Xiping Xin ${ }^{1}$ and Peeyush K Lala ${ }^{1,2,3^{*}}$
}

\begin{abstract}
Background: Tumor-induced lymphangiogenesis facilitates breast cancer progression by generating new lymphatic vessels that serve as conduits for tumor dissemination to lymph nodes and beyond. Given the recent evidence suggesting the implication of C-C chemokine ligand 21/chemokine receptor 7 (CCL21/CCR7) in lymph node metastasis, the aim of our study was to define the role of this chemokine pair in breast cancer-associated lymphangiogenesis.

Methods: The expression analysis of CCL21/CCR7 pair and lymphatic endothelial cell (LEC) markers in breast cancer specimens was performed by means of quantitative real-time PCR. By utilizing CCR7 and CCL21 gene manipulated breast cancer cell implants into orthotopic sites of nude mice, lymphatic vessel formation was assessed through quantitative real-time PCR, immunohistochemistry and immunofluorescence assays. Finally, the lymphangiogenic potential of CCL21/CCR7 was assessed in vitro with primary LECs through separate functional assays, each attempting to mimic different stages of the lymphangiogenic process.
\end{abstract}

Results: We found that CCR7 mRNA expression in human breast cancer tissues positively correlates with the expression of lymphatic endothelial markers LYVE-1, podoplanin, Prox-1, and vascular endothelial growth factor-C (VEGF-C). We demonstrated that the expression of CCL21/CCR7 by breast cancer cells has the ability to promote tumor-induced lymph-vascular recruitment in vivo. In vitro, CCL21/CCR7 chemokine axis regulates the expression and secretion of lymphangiogenic factor VEGF-C and thereby promotes proliferation, migration, as well as tube formation of the primary human LECs. Finally, we showed that protein kinase B (AKT) signaling pathway is the intracellular mechanism of CCR7-mediated VEGF-C secretion by human breast cancer cells.

Conclusions: These results reveal that CCR7 and VEGF-C display a significant crosstalk and suggest a novel role of the CCL21/CCR7 chemokine axis in the promotion of breast cancer-induced lymphangiogenesis.

Keywords: CCL21 chemokine, CCR7 chemokine receptor, Vascular endothelial growth factor-C, Protein kinase B, Lymphangiogenesis, Breast cancer

\section{Background}

Chemokines and their receptors play essential roles in tumor biology including leukocyte recruitment, tumor cell growth and survival, angiogenesis, and metastasis [1-7]. Among them, $\mathrm{C}-\mathrm{C}$ chemokine ligand 21/chemokine receptor 7 (CCL21/CCR7) pair promotes growth and metastasis of many tumor types including melanomas, breast,

\footnotetext{
*Correspondence: pklala@uwo.ca

'Department of Anatomy \& Cell Biology, Schulich School of Medicine and Dentistry, Western University, 1151 Richmond St, London, ON N6A 5C1, Canada

${ }^{2}$ Department of Oncology, Schulich School of Medicine and Dentistry, Western University, 790 Commissioners Rd. E, London, ON N6A 4L6, Canada Full list of author information is available at the end of the article
}

thyroid, colon, head, and neck cancers [8-14]. CCR7 has emerged as an important marker in the prediction of axillary lymph node metastasis in breast carcinomas, particularly since CCR7 over-expression correlates with larger primary tumors, deeper lymphatic invasion and poorer survival rates $[10,13,15]$. In vivo studies revealed that metastatic tumor formation is decreased when CCL21 expression is knocked down in secondary lymphoid organs, since this diminishes both the chemotactic and antiapoptotic effects of CCR7-expressing tumor cells [14]. Similarly, CCL21/CCR7 pair seems to play an important role in the lymphangiogenesis associated with pancreatic cancer $[16,17]$ and - due to its chemotactic

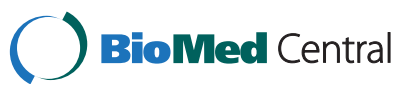

(c) 2015 Tutunea-Fatan et al.; licensee Biomed Central. This is an Open Access article distributed under the terms of the Creative Commons Attribution License (http://creativecommons.org/licenses/by/4.0), which permits unrestricted use, distribution, and reproduction in any medium, provided the original work is properly credited. The Creative Commons Public Domain Dedication waiver (http://creativecommons.org/publicdomain/zero/1.0/) applies to the data made available in this article, unless otherwise stated. 
properties - this chemokine axis is involved in the lymphatic spread of melanoma cells [18]. However, while the complete picture on the role and involvement of CCL21/ CCR7 pair in breast cancer is still undergoing development, there are at least two areas in which this axis has shown to be actively involved, often through vascular endothelial growth factor C (VEGF-C) mediated signaling, namely: lymph nodes metastasis, and immune response modulation [18-23].

VEGF-C production by tumor cells is recognized as the chief promoter of tumor-associated lymphangiogenesis by stimulating growth and differentiation of lymphatic endothelial cell precursors [24-26]. Tumor-derived VEGF-C can also mediate lymphangiogenesis-independent actions that promote breast cancer invasiveness and metastasis $[27,28]$. We had earlier reported that overexpression of cyclooxygenase-2 (COX-2) in breast cancer cells - resulting in increased prostaglandin E2 (PGE2) levels in the tumor milieu - promotes metastasis by multiple mechanisms including stimulation of tumor cell migration [29,30], invasiveness [31], tumor-associated angiogenesis [29], and lymphangiogenesis [32-34] caused by an upregulation of VEGF-C secretion via prostaglandin EP1/EP4 receptors $[27,32,33]$. Along the same lines, EP2 receptor has been shown to be involved in COX-2 mediated lymphangiogenesis [35]. However, neither COX-2 inhibitors nor EP4 antagonists could completely abrogate VEGF-C production by highly metastatic breast cancer cells indicating that additional mechanisms are involved in VEGF-C secretion. While prior studies have established that COX-2 secretion by breast cancer cells can upregulate CCR7 expression via activation of EP2/EP4 receptors $[20,36]$ to enhance their invasive capacity, a possible link between CCR7 signaling and VEGF-C expression/secretion has remained untested so far. Therefore, the objective of the present study was to investigate whether CCL21/ CCR7 signaling promotes breast cancer-associated lymphangiogenesis through CCR7-dependent stimulation of VEGF-C secretion followed by LECs activation towards the development of new lymphatic vessels. This objective was achieved by a combination of in situ, in vivo, and in vitro approaches.

Here, we have established that CCR7 correlates with the expression of lymphatic endothelial cell markers in a panel of human breast cancer tissues as well as with the expression of the lymphangiogenic factor VEGF-C. By utilizing CCR7 or CCL21 gene manipulated breast cancer cell implants in vivo we have shown that the analyzed chemokine pair promotes host lymphatic vessel recruitment and growth. Moreover, CCL21/CCR7 chemokine axis has the ability to promote lymphatic endothelial cells proliferation, migration, as well as tube formation in vitro, and this axis also regulates the expression of lymphangiogenic factor VEGF-C by breast cancer cells. Finally, the phosphorylation of AKT pathway constitutes the intracellular mechanism underlying CCR7-mediated VEGF-C synthesis. Our study adds new elements to the multifaceted role of CCL21/CCR7 chemokine pair in mammary malignancy by revealing a novel role of this chemokine axis in breast cancerassociated lymphangiogenesis that might be relevant to future therapies.

\section{Results}

Role of CCL21/CCR7 pair in mediation of VEGF-C secretion by breast cancer cells

Prior to the investigation of the role of CCL21/CCR7 pair in VEGF-C production, we have screened the constitutive expression of CCR7, CCL21, and VEGF-C in two well differentiated, luminal type (T47D, MCF-7) and two poorly differentiated basal type (Hs578t, MDA-MB-231) breast cancer cell lines (Additional file 1: Figure S1A and B). Based on these preliminary results, MDA-MB-231 breast carcinoma cell line - that is characterized by an invasive phenotype - was selected for its ability to express/ secrete high levels of VEGF-C, which makes it adequate for use in a loss-of-function model. Conversely, for the gain-of-function approach, MCF-7 cell line was selected since expresses/secretes relatively low levels of VEGF-C. In this regard, CCR7 expression in MDA-MB-231 cells was knocked down with shRNA targeting CCR7 gene and the effectiveness of transfection was assessed by means of Western blot, real-time PCR, and quantitative real-time PCR (Figure 1A to C). Of note, low levels of CCR7 expression correlates with significant downregulations in VEGF$\mathrm{C}$ protein and mRNA expressions (Figure 1D to F). To determine whether CCL21/CCR7 interaction regulates the secretion of lymphangiogenic factor VEGF-C, CCR7 shRNA and parental MDA-MB-231 cells were incubated with and without human CCL21/6Ckine (350 ng/ml) for 24 hours. While exogenous CCL21 has stimulated VEGF$C$ production by parental cells, the secretion level of VEGF-C from CCR7 shRNA transfected tumor cells has decreased significantly. The level was significantly lower compared to CCL21 treated or untreated parental cells or scrambled shRNA transfected cells (Figure 1G). Moreover, the proposed molecular mechanism responsible for the regulation of VEGF-C was analyzed in MCF-7 mock and MCF-7-CCL21-knocked in (KI) breast cancer cells and the efficacy of nucleotransfection is presented in Figure $1 \mathrm{H}$ and I. Quantitative PCR, Western blot, and ELISA confirmed that CCL21/CCR7 pair has the ability to regulate the expression of the lymphangiogenic factor VEGF-C in the analyzed MCF-7 breast cancer cells (Figure 1H - L). Overall, these findings suggest that CCL21/CCR7 pair has the potential to regulate VEGF-C expression/secretion in the analyzed breast cancer cell line models. 


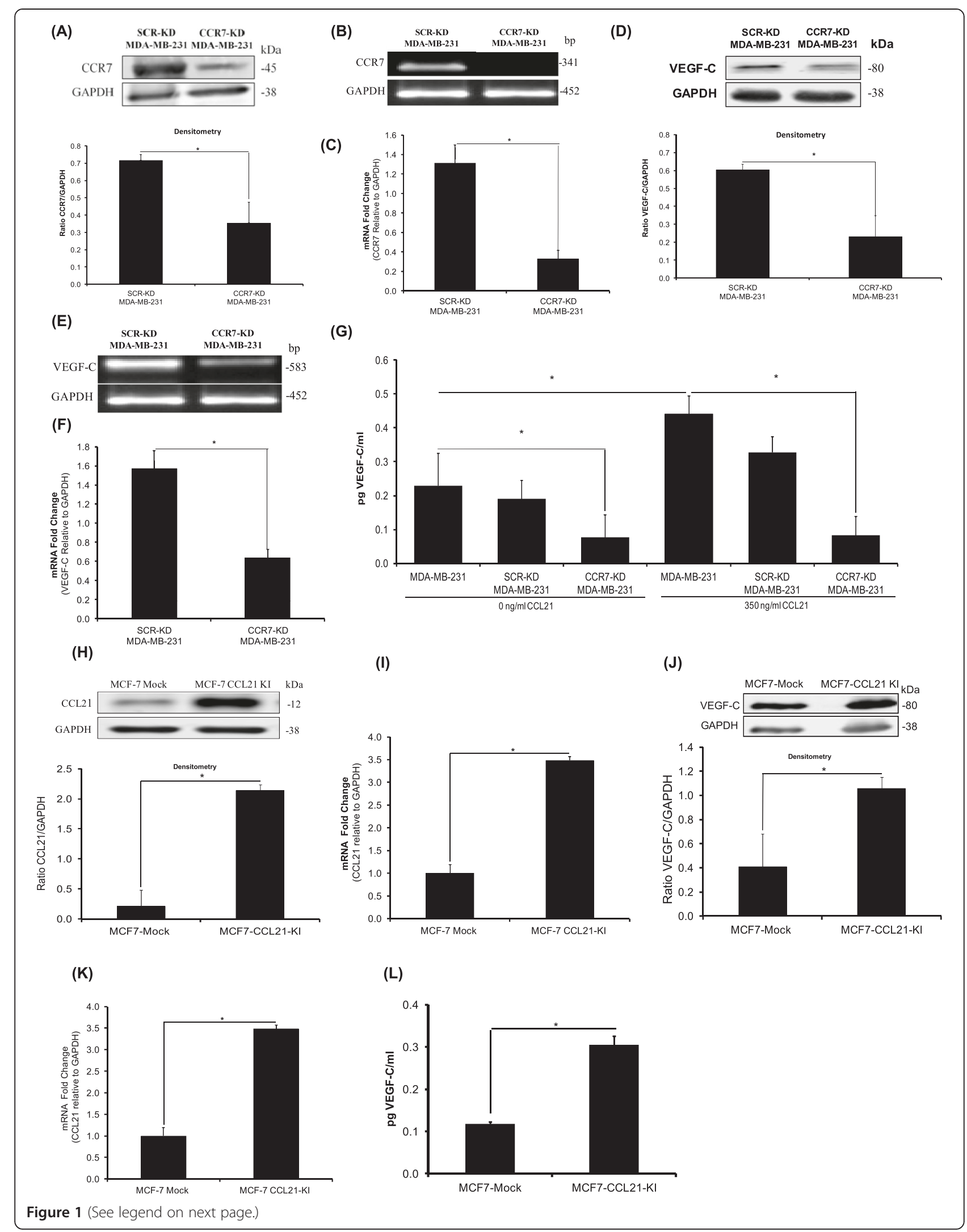


(See figure on previous page.)

Figure 1 CCR7 promotes expression and secretion of lymphangiogenic factor VEGF-C. (A) Western blots (B) real-time PCR and (C) quantitative real-time PCR validating CCR7 knockdown in MDA-MB-231 cells versus control shRNA. (D) Western blot, (E) real time PCR and (F) quantitative real-time PCR analysis outlining decreased VEGF-C expression in MDA-MB-231 CCR7 shRNA cells versus control shRNA. (G) ELISA demonstrates that VEGF-C protein concentration in conditioned media from CCL21 treated/untreated CCR7-KD cells decreased significantly compared to parental or scrambled MDA-MB-231 cells. (H) Western blot and (I) quantitative real-time PCR validating CCL21 overexpression in MCF-7 cells. (J) Western blot, (K) quantitative PCR outlining increased VEGF-C expression in MCF-7 CCL21 cells versus control mock. (L) VEGF-C protein concentration in conditioned media from MCF-7 CCL21 and control cells as measured by ELISA. In (A-K) data are represented as mean \pm SD $(n=4)$, except (G) and (L) where data are represented as mean $\pm S D(n=3)$. $\left(^{*}\right)$ indicates statistical significant differences $(p<0.005)$.

\section{Signaling mechanisms of CCR7-mediated VEGF-C secretion}

Prior studies have documented the role of phosphatidylinositol 3-kinase (PI3K) and its downstream mediator protein kinase $\mathrm{B}(\mathrm{AKT})$ in the survival and invasiveness of head and neck carcinoma cells through CCL21/CCR7 interaction [37,38]. Furthermore, extracellular signal-regulated kinase (ERK1/2) pathway is involved in cell cycle progression and survival of nonsmall cell lung carcinoma cells resulting from CCR7 activation $[39,40]$.

To investigate whether AKT and ERK1/2 pathways are downstream activated by CCL21-CCR7 binding, the phosphorylation status of both pathways was assessed in MDA-MB-231 breast cancer cells. As expected, an increase in phosphorylation of AKT and ERK1/2 was observed for the entire duration of stimulation with CCL21/6Ckine (Figure 2A, B). To assess whether the phosphorylation of both proteins was dependent on the activation of CCR7, MDA-MB-231 cells were treated with various concentrations of CCR7 antibody $(0,5,10$, $20 \mu \mathrm{g} / \mathrm{ml}$ ) before stimulation with CCL21/6Ckine. When CCR7 was blocked by its neutralizing antibody, the phosphorylation status of AKT and ERK1/2 was significantly decreased (Figure 2C, D). Similarly, the addition of PI3K/AKT and ERK1/2 specific inhibitors significantly reduced the effect of CCL21 on activation of both pathways (Figure $2 \mathrm{E}-\mathrm{G}$ ).

Finally, to test the functional roles of PI3K/AKT and/or ERK1/2 pathways in CCL21-induced VEGF-C secretion, MDA-MB-231 cells were pre-treated with various concentrations of PI3K inhibitor (LY294002 at 25, 50, and $75 \mu \mathrm{M}$ ), Akt-1/2 inhibitor (at 2.5, 5, and $10 \mu \mathrm{M}$ ), and ERK1/2 inhibitor (U0126 at 5, 10, and $15 \mu \mathrm{M}$ ) and then treated with CCL21/6Ckine $(350 \mathrm{ng} / \mathrm{ml})$ for 24 hours. Following that, the supernatants were collected and subjected to a VEGF-C ELISA. Both PI3K and AKT inhibitors yielded a significantly reduced VEGF-C secretion when compared with CCL21 treatment alone (Figure 2H, I), whereas no significant difference was observed for U0126 treatment (Figure 2J). As such, it can be affirmed that the activation of PI3K/AKT, but not ERK1/2 signaling pathway downstream of CCR7 is involved in the regulation of VEGF-C secretion.

\section{CCL21/CCR7 pair has lymphangiogenic potential in vitro}

Lymphatic vessel formation is a complex biological process that can be approached in vitro through separate assays, each attempting to mimic a different stage of the lymphangiogenic process such as: proliferation, migration, and formation of capillary-like tubes [41]. Within the limited scope of the current study, primary HMVECs-dLy were employed as an in vitro model of LECs and their CCR7 and CCL21 expressions were verified at the mRNA and protein levels. Agarose gel electrophoresis of real-time PCR products from HMVECdLy cells showed that both the chemokine receptor and ligand are expressed at the mRNA level (Figure 3A). On the other hand, lysates from cultured HMVEC-dLy cells were assayed by Western blot and CCR7 protein expression was detected at $45 \mathrm{kDa}$ while only traces of CCL21 were observed (Figure 3B). Moreover, CCL21 protein secretion by HMVEC-dLy cells was quantified in 2D and 2D-matrix conditions (Matrigel was used because CCL21 is strongly matrix-binding). One important aspect to be emphasized is that CCL21 chemokine ligand is secreted as a small molecular weight protein that is readily immobilized within the extracellular matrix by binding to sulfated proteoglycans [42]. As such, there was no surprise that the determined bound CCL21 protein fraction was about twofold higher than the soluble fraction, but the overall CCL21 secretion by HMVEC-dLy was constitutively present at very low levels (Figure 3C). Therefore, serum-starved LECs were treated with various concentrations of exogenous CCL21/6Ckine (100-350 ng/ml) and their proliferation rates (BrdU uptake) increased significantly (Figure 3D). Conversely, when CCR7 activation was blocked with CCR7-neutralizing antibody $(10 \mu \mathrm{g} / \mathrm{ml})$, LECs proliferation significantly decreased to serum-free level (Figure 3E). LECs also responded to the chemotactic effect of CCL21 by increased migration (Figure 3F, G). Conversely, in the presence of various concentrations of CCR7neutralizing antibody $(5,10,20 \mu \mathrm{g} / \mathrm{ml})$, CCL21mediated LECs migration was significantly inhibited (Figure $3 \mathrm{H}$ ). Finally, the extent of tube-like structures formed by LECs increased significantly with increasing concentrations of CCL21/6Ckine (100-350 ng/ml) (Figure 3I, J). By contrast, CCL21 mediated tubulogenesis was blocked by CCR7 neutralizing antibody 


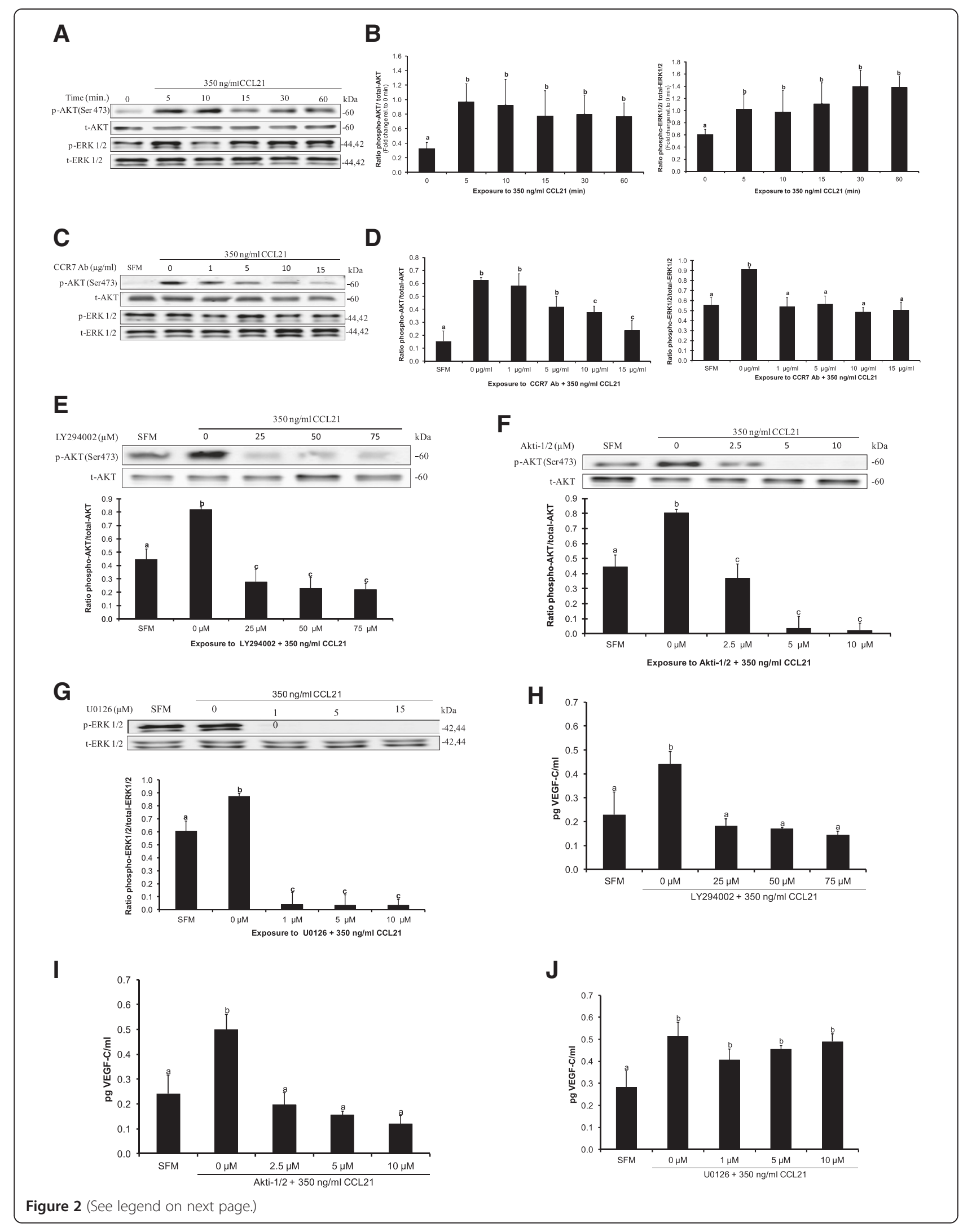


(See figure on previous page.)

Figure 2 CCR7 activation by CCL21 regulates VEGF-C secretion via the PI3K/AKT signaling pathway. (A) Western blot time course analysis of AKT and ERK1/2 activation in MDA-MB-231 cells following treatment with CCL21 for a total of 60 minutes. Phosphorylation of AKT at Ser 473 and ERK1/2 is observed over the entire duration of stimulation compared to control, untreated cells. (B) Densitometric analysis revealed that phosphorylation of both pathways is significantly induced after 5 min of CCL21 treatment. (C) Western blot and (D) Densitometric analysis indicating that CCL21-induced phosphorylation is dependent on CCR7 activation. Western blot demonstrating that PI3K/AKT inhibitors LY 294002 (E) Akt-1/2 (F), and ERK1/2 inhibitor U0126 (G) can block CCL21/CCR7-mediated phosphorylation in an inhibitor dose-dependent manner. For all experiments, total AKT and total ERK1/2 confirmed the equivalent loading of lanes. (H-J) PI3K/AKT but not ERK1/2 specific inhibitors significantly block CCL21 mediated VEGF-C secretion measured with ELISA. Data are represented as means $\pm S D(n=3)$. Different superscripts indicate statistically significant differences $(p<0.05)$.

(Figure 3K, L). To determine whether CCL21/CCR7 acts through the regulation of VEGFR-3 ligand, LECs were treated with CCL21 in the presence and absence of VEGFR-3 neutralizing antibody $(1,2.5,5 \mu \mathrm{g} / \mathrm{ml})$. Blocking VEGFR-3 significantly has reduced CCL21-induced LECs proliferation, migration, and tube formation (Figure 3M). Based on these results, it can be inferred that within the framework of the investigated in vitro model, CCL21/ CCR7 pair has a direct lymphangiogenic potential through stimulation of the lymphangiogenic traits of LECs. Additionally, CCL21/CCR7 pair interacts in a ligandindependent manner with VEGFR-3 expressed by LECs to drive their lymphangiogenic response.

\section{CCL21/CCR7 pair promotes lymph-vascular recruitment in vivo}

To validate our in vitro observations, Directed In Vivo Lymphangiogenic Assay (DIVLA) was conducted, as reported in the past [43]. In brief, the angioreactors containing basement membrane extract and breast cancer cells were implanted subcutaneously into the dorsal flanks of nude mice and lymphatic vessel formation was assessed through multiple approaches. Host lymphatic endothelial cells that invaded the angioreactors associated with different conditions were quantified with an immunofluorescence assay for LYVE1 and Prox1. The results revealed that the recruitment of LYVE1 and Prox1 labelled lymphatic endothelial cells was significantly higher in the angioreactors containing MCF-7CCL21-KI cells when compared with their controls. Similarly, this recruitment was impaired when CCR7 was knocked down, as observed in the MDA-MB-231CCR7-KD angioreactors compared to control, MDAMB-231-mock angioreactors (Figure 4B). Relative LECs recruitment measured with quantitative real-time PCR for LYVE1 mRNA expression in cellular contents of the angioreactors also revealed a similar phenomenon: a significantly higher recruitment with MCF-7-CCL21-KI than with MCF-7-mock cells; and a significantly lower recruitment with MDA-MB-231-CCR7-KD than with MDA-MB-231 mock cells (Figure 4C). For a direct quantification of MVD and LVD, serial cryosections of angioreactors were performed and dual immunostaining was subsequently used to visualize lymphatics (LYVE1/Prox1/
Podoplanin) and blood vessels (CD31) by means of "hot spot" method [34,43]. Higher MVD and LVD were observed in MCF-7-CCL21-KI sections when compared to control (MCF-7 mock). Similarly, lower densities were observed in MDA-MB-231-CCR7-KD sections than in MDA-MB-231 mock (Figure 4D - G, quantification 4I). Finally, the addition of recombinant VEGF-C to the angioreactors containing MDA-MB-231-CCR7-KD cells has rescued lymphatic vessel formation to the same level observed with control MDA-MB-231 (Figure 4H). To verify the in vivo expression of CCR7 by LECs, angioreactors containing only lymphangiogenic growth factors were implanted into nude mice and quantitative real-time PCR analysis was performed to analyze the content of the tubes (Additional file 2: Figure S2B). Thus, according to our in vivo results, CCL21/CCR7 pair is a positive regulator of lymphangiogenesis.

\section{CCR7 expression correlates with lymphangiogenic markers in breast cancer samples}

To characterize the role of CCL21/CCR7 in situ, we used a panel of breast cancer tissues $(n=105)$ collected from the primary tumor site. The demographic and clinical characterization of the samples is summarized in Additional file 3: Table S1. In brief, the majority of the tissues were classified as invasive mammary carcinomas characterized by various grades of differentiations: grade III (62\%) and grade II (24\%). At first, quantitative realtime PCR was employed to compare the expression profile of CCR7, CCL21, and VEGF-C in primary tumor and adjacent breast tissues (control). The stability in expression levels of two common housekeeping genes (GAPDH and ACTB) was verified across the entire panel of tissues. Of note, the level of CCR7 mRNA in tumor tissues was significantly higher than that in the control samples. A trend similar to CCR7 was observed for VEGF-C. However, CCL21 mRNA expression in tumors was not significantly different when compared to controls (Figure 5A). Moreover, it was found that CCR7 mRNA expression is positively correlated with lymphvascular markers (LYVE1, podoplanin) and VEGF-C in breast cancer specimens while no correlation with endothelial marker CD31 was observed (Figure 5B - E). As for CCL21 expression, a weak correlation with lymph-vascular 


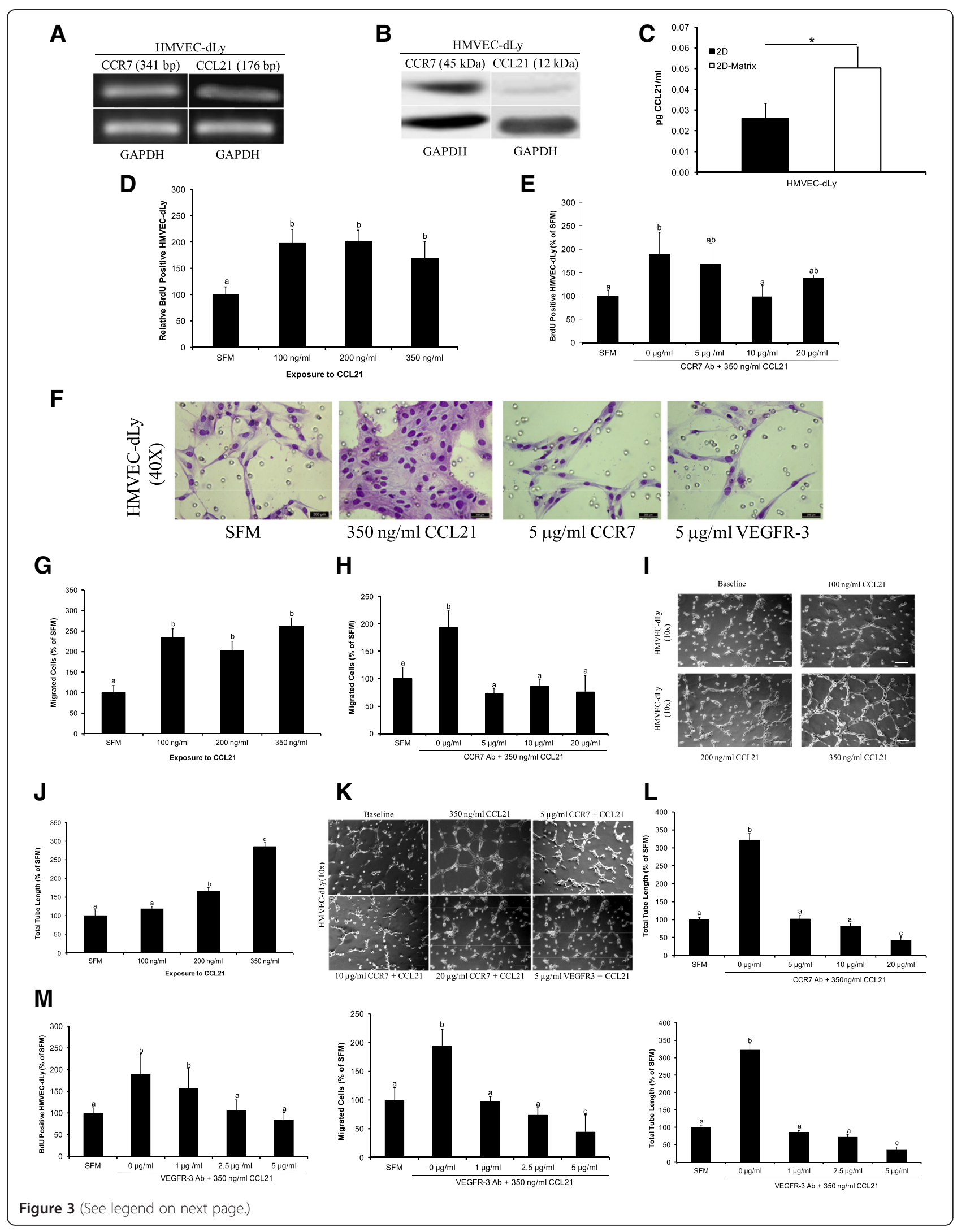


(See figure on previous page.)

Figure 3 CCL21/CCR7 axis has lymphangiogenic potential in vitro. (A) Real-time PCR of CCR7 and CCL21 mRNA expression in HMVEC-dLy. (B) Western blot of CCR7 and CCL21 protein expression in HMVEC-dLy. GAPDH was used as an internal control. (C) CCL21 protein secretion by HMVEC-dLy as measured by ELISA. Data are represented as mean $\pm \mathrm{SD}(n=3)$. $\left(^{*}\right)$ indicates significant difference $(p<0.05)$. (D) HMVEC-dLy proliferation in response to CCL21/6Ckine $(0,100,200,350 \mathrm{ng} / \mathrm{ml})$ performed by the measurement of BrdU. Data are presented as mean $\pm S D(n=4, p<0.001)$. (E) HMVEC-dLy proliferation in response to CCR7 neutralizing antibody $(0,5,10,20 \mu \mathrm{g} / \mathrm{ml})$. Data are presented as mean $\pm S D(n=4, p<0.0003)$. (F) Representative images of HMVEC-dLy migration (40x magnification). (G) Quantification of HMVEC-dLy cellular migration in response to CCL21/6Ckine $(0,100,200$, and $350 \mathrm{ng} / \mathrm{ml})$. (H) Quantification of HMVEC-dLy migration in response to CCR7 neutralizing antibody $(0,5,10,20$ Mg/ml). Bars in (G, H) represent mean number of migrated cells $\pm S D(n=4, p<0.005)$. (I) Representative micrographs of HMVEC-dLy tubular network formation in response to CCL21/6Ckine $(0,100,200,350 \mathrm{ng} / \mathrm{ml})$. Bar equals $100 \mu \mathrm{m}$. (J) Quantification of total length of tubular structures formed by HMVEC-dLy corresponding to (I) as determined by ImageJ. (K) Representative images of inhibition of HMVEC-dLy tubular network formation. Bar equals 100 $\mu \mathrm{m}$. (L) Quantified HMVEC-dLy tube formation corresponding to images shown in (K). In ( $\mathbf{J}$ and $\mathbf{L}$ ) data are presented as mean \pm SD ( $n=4$, $p<0.0001)$. (M) Quantified HMVEC-dly proliferation, migration, and tube formation in response to treatment with VEGFR-3 neutralizing antibody $(0,1,2.5,5 \mu \mathrm{g} / \mathrm{ml})$. Data are presented as mean $\pm \mathrm{SD}$. Different superscripts represent a statistical significant difference.

markers was observed (data not included). These results suggest a clinical association between CCR7 expression and lymph-vascular recruitment in primary breast tumor.

\section{Discussion}

Lymphangiogenesis, the growth of new lymphatic vessels, has an important role in the complex pathology of tumoral processes in general, and in that of breast cancer in particular $[24,25,44,45]$. Furthermore, lymphatics have started to be reclassified as active, rather than passive conduits in cancer, since they are able to fine tune the balance between peripheral tolerance and immunity that facilitates host immune tolerance to tumor invasion $[46,47]$. The newly cited roles of lymphatics include the indirect suppression of T-cell function, the inhibition of dendritic cell (DC) maturation, as well as a direct effect on T-cell tolerance [48].

Within the immunological context, the two major leukocyte subsets whose surfaces express CCR7 are dendritic and $\mathrm{T}$ cells such that CCR7 is known to have strong implications on both central and peripheral tolerance [49]. On the other hand, CCL21 is constitutively expressed by the lymphatic endothelium of multiple organs, high endothelial venules of lymph nodes and Peyer's patches, as well as stromal cells in T cell rich areas of lymph nodes, and spleen [50]. The wide physiological distribution, combined with the complex and multifaceted roles in lymph node trafficking could be one of the reasons for which CCL21/CCR7 axis has been identified as a viable candidate for the fast dissemination of breast cancer cells developed in the immediate proximity of the lymphatics. Furthermore, the lymphangiogenic factor VEGF-C is one of the known promoters of intra- and peritumoral lymphatic development and a facilitator of tumor cell dissemination [26,33,51]. However, molecular regulation of lymphangiogenesis extends to many other types of interactions that are often placed outside of the conventional VEGF family of prolymphangiogenic factors [17,52-54].
The involvement of CCL21/CCR7 pair in migration and guidance of the cells detached from the primary tumor towards draining lymphatics is believed to play a significant role in the subsequent metastatic evolution of the disease $[18,19]$. Present results, combined with our earlier report of pro-migratory functions of VEGF-C [27], and reported VEGF-C mediated stimulation of CCL21 secretion by LECs [21], endorses the idea that the interplay/crosstalk between CCL21 chemokine and VEGF-C promotes breast cancer progression through several distinct, but complementary mechanisms. Our present results prompt for the first time that a closed loop/circular communication exists between CCL21/ CCR7 and VEGF-C/VEGFR-3 axes, in a sense that not only VEGF-C promotes CCL21 secretion by LECs [21], but also that CCR7 activation stimulates VEGF-C synthesis by tumor cells and thus drives lymphangiogenesis. Indeed, our results show that inhibition of CCR7 gene translates into significant decreases of VEGF-C expression in the analyzed breast cancer cells. In addition, our study reports a significant inducible VEGF-C secretion in MDA-MB-231 cells in response to CCR7 activation (Figures 1, 2, and 4). Moreover, CCL21 has been found to regulate lymphangiogenesis in a LEC-dependent manner (Figure 3): 1) directly, through the stimulation of the lymphangiogenic traits of LECs (e.g. proliferation, migration and tubular network formation); and 2) indirectly, through the modulation of VEGFR-3 signaling pathway. An overall summary of these findings is depicted in the schematic of Figure 6. Furthermore, these results corroborate well with our in situ findings outlining a strong correlation between CCR7 and VEGF-C expression in human breast cancer tissues. However, CCR7 may activate other lymphangiogenic factors to mediate lymphatic vascularisation, such that a full analysis of its prolymphangiogenic profile/signature represents an avenue that to be explored in the future.

Previous studies indicate that CCR7-mediated signaling required for invasive and pro-survival functions in 


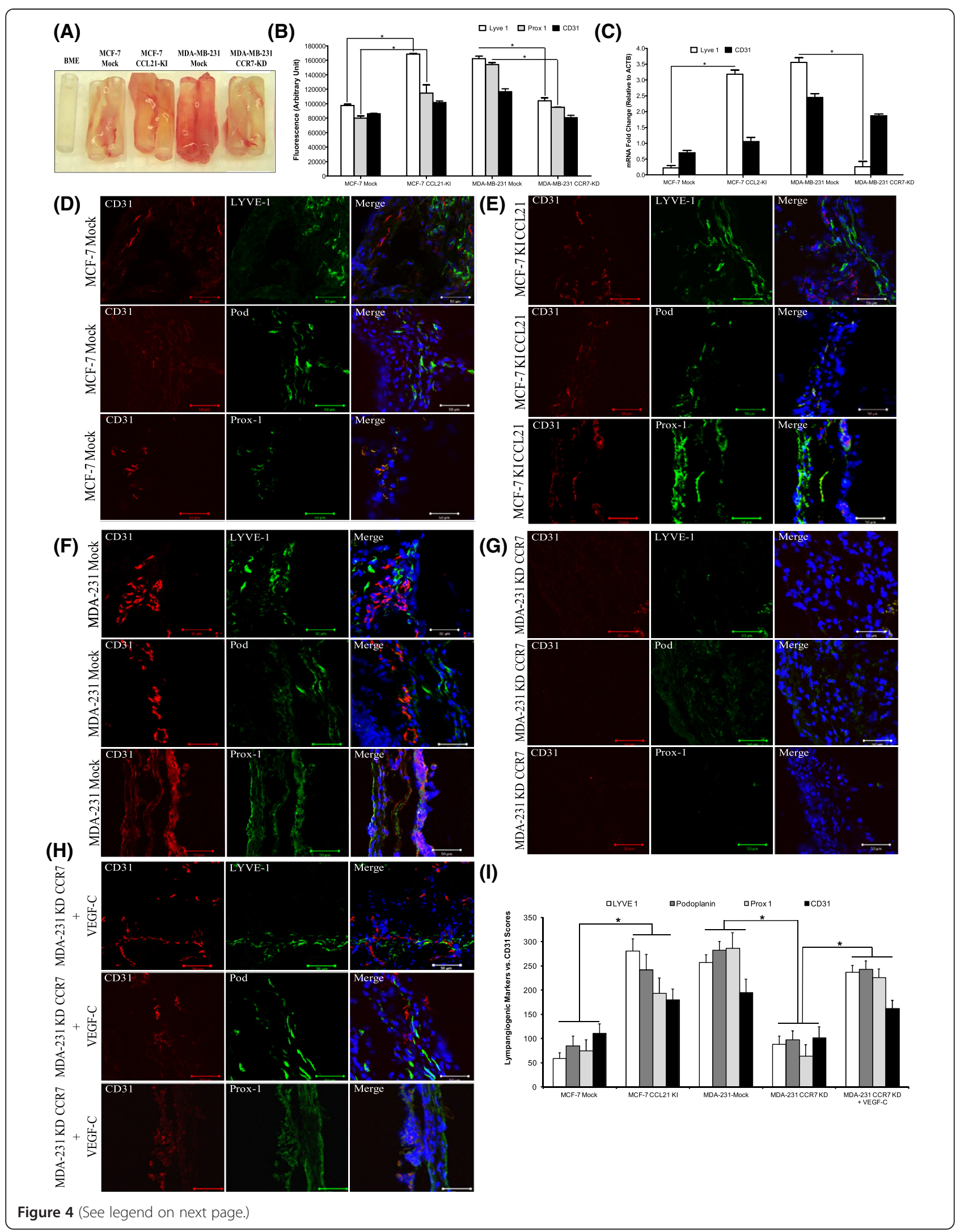


(See figure on previous page.)

Figure 4 CCL21/CCR7 axis has lymphangiogenic potential in vivo. (A) Macroscopic digital images of angioreactors collected with surrounding tissues. (B) Fluorescence assay analysis of LYVE1, Prox1, and CD31 markers as expressed by mouse lymphatic endothelial cells and blood vascular endothelial cells recruited into the angioreactors. Data are presented as mean relative fluorescent units \pm SEM. (*) indicates significant difference $(p<0.005)$. (C) Quantitative real-time PCR analysis of LWE1 and CD31 mRNA expression in the cellular contents of angioreactors. Expression levels are normalized to actin (ACTB). ( $\left(^{*}\right)$ indicates significant difference $(p<0.05)(n=4)$. (D to G). Representative images of immunofluorescence localization of CD31 (red), LYVE1 (green), Podoplanin (green), and Prox1 (green) in serial sections of angioreactors containing MCF-7 mock vs. CCL21 KI MCF-7 cells (D), (E) and MDA-MB-231 mock vs. CCR7 KD MDA-MB-231 cells (F), (G). Nuclei are stained with DAPI (blue). Scale bar equals $50 \mu \mathrm{m}$. (H) Representative images of immunofluorescence localization of CD31 (red), LYVE1 (green), Podoplanin (green), and Prox1 (green) in serial sections of angioreactors containing CCR7 KD MDA-MB-231 cells and recombinant human VEGF-C (30 ng/ $\mu$ l). Nuclei are stained with DAPI (blue). Scale bar equals $50 \mu \mathrm{m}$. (I) Quantification of MVD and LVD. "Hot spot" scores for CD31-LYVE1, CD31-Podoplanin, and CD31-Prox1 were calculated by means of Image J (40x magnification). Data are presented as mean of "hot spot" \pm SEM.

head and neck cancer cells is mediated by PI3K/AKT pathway [14], whereas CCR7-mediated cell cycle progression in lung cancer cells utilizes ERK1/2 pathway [39]. We demonstrate here that CCR7 activation by CCL21 binding can induce a significant increase in both AKT and ERK1/2 phosphorylation in breast cancer cells; however, only the former pathway is required for VEGF$\mathrm{C}$ up-regulation and secretion. While this result constitutes a new finding in the context of CCR7 chemokine receptor, a similar molecular mechanism was confirmed for insulin-like growth factor-I receptor-mediated VEGF$\mathrm{C}$ secretion in lung carcinoma cells [55].

Another important finding in our study is that CCL21/ CCR7 axis has a significant effect on LECs proliferation, migration, and tubular network formation and this effect seems to be regulated by means of VEGFR-3 signaling pathway. However, the precise molecular mechanisms involved in LEC-dependent/tumor-independent lymphangiogenesis remain to be elucidated. Interestingly, neither CCL21 stimulation nor CCR7 receptor blocking induced dose-dependent effects on HMVEC-dLy proliferation and migration, a phenomenon that could be explained perhaps through chemokine receptor saturation followed by its desensitization and internalization [56]. Another important aspect to be emphasized here is that by contrast with the surveyed literature $[57,58]$ reporting that lymphatic cells are capable of secreting CCL21, HMVEC-dLy cells used in the present study were found as weak producers of CCL21 chemokine. One possible explanation of this result could be the substantial changes in gene expression induced by culture in primary cells that might be the cause of the loss of CCL21 production [59]. Cell culture might therefore alter some of the core features of HMVEC-dLy cells.

Our in vivo findings indicate that CCR7 is expressed by LECs and therefore promotes LECs recruitment and lymphangiogenesis through the regulation of the expression/secretion of VEGF-C by human breast cancer cells. To recapitulate, we have created a directed in vivo lymphangiogenic assay (DIVLA) wherein in as a loss-of- function model the CCR7 expression was knockdown and a significant decrease in lymphatic vessel density was remarked, a phenomenon that was rescued by the addition of lymphangiogenic factor VEGF-C. These results reiterate the effects which we have observed in our comparable gain-of-function model, in which an increase in CCL21 expression associates well with an increase in lymphatic vessel density.

Since our in vitro and in vivo studies have established the roles of CCR7/CCL21 and VEGFR3/VEGF-C axes in breast cancer induced lymphangiogenesis, we have postulated that CCR7 and VEGF-C expressions will be noticeably different in tumor tissues when compared to their non-tumor counterparts. Herein our study provides evidence that the expressions of both CCR7 and VEGF$\mathrm{C}$ were significantly upregulated in the analyzed breast carcinoma samples when compared with control nontumor tissues. Interestingly, no significant difference in CCL21 expression was noted between tumor and nontumor regions. Similar variation patterns were also observed for CCR7 and CCL21 in pancreatic cancer [16], for CCL21 in squamous cell carcinoma [60] or for CCR7 and VEGF-C in pancreatic ductal adenocarcinoma [17]. In addition, we have identified positive correlations between the CCR7 expression and lymphatic endothelial markers in the analyzed panel of breast cancer tissues.

\section{Conclusions}

Collectively, these results add newer insights into the multifaceted role played by the CCL21/CCR7 chemokine pair in mammary malignancy, prompting for the first time towards the involvement of this chemokine axis in the complex mechanics of breast cancer-induced lymphangiogenesis The proven therapeutic effectiveness of blocking CCR7-mediated CCL21 signaling [61] combined with the promising outlook [62] of phase 1 DC-CCL21 trial in lung cancer and melanoma patients [63], suggests that the inherent value of the present study is more than apparent. 
(A)

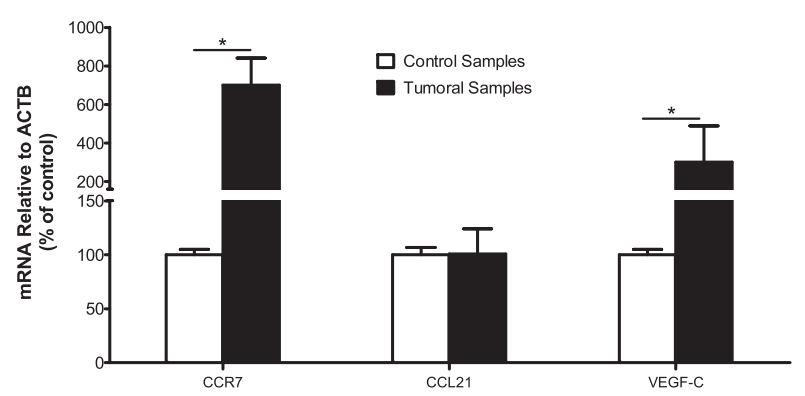

(C)

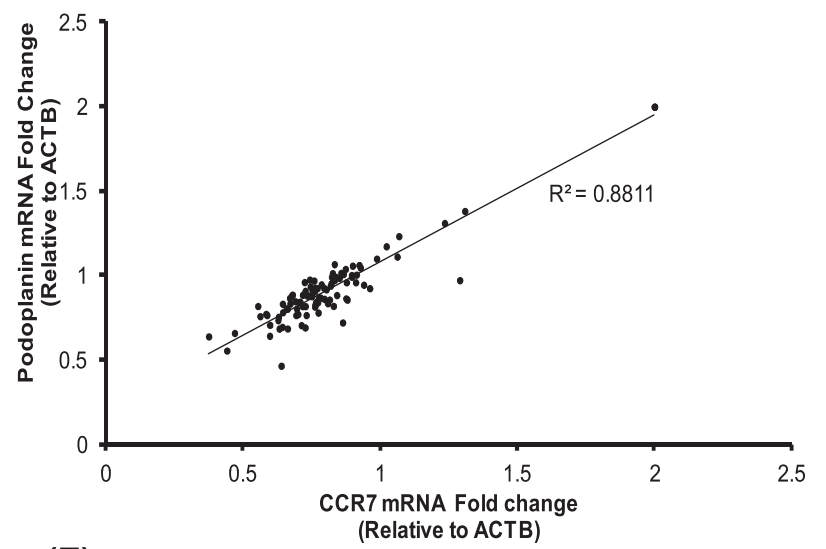

(E)

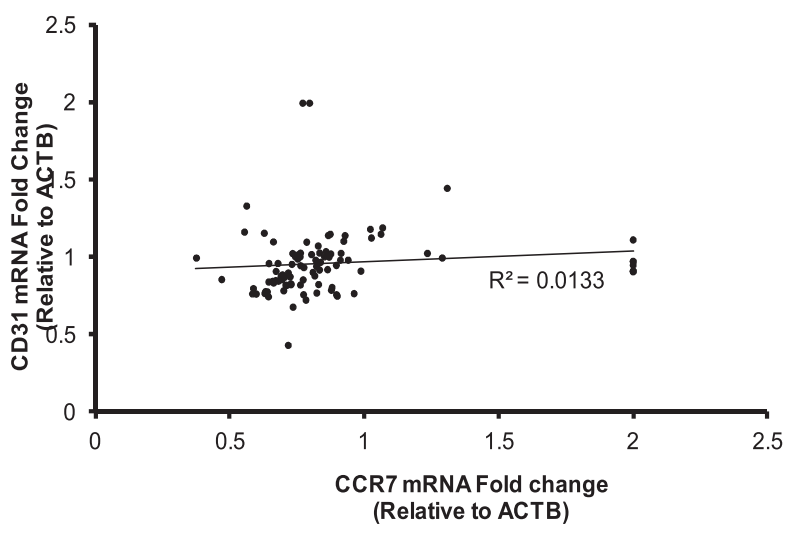

(B)

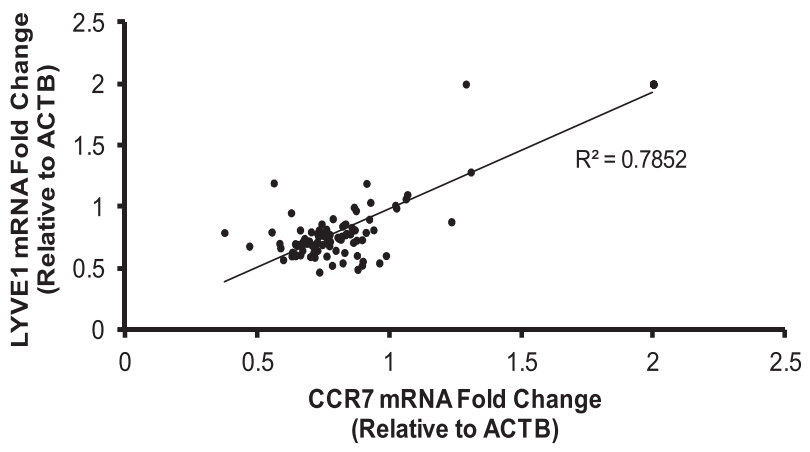

(D)

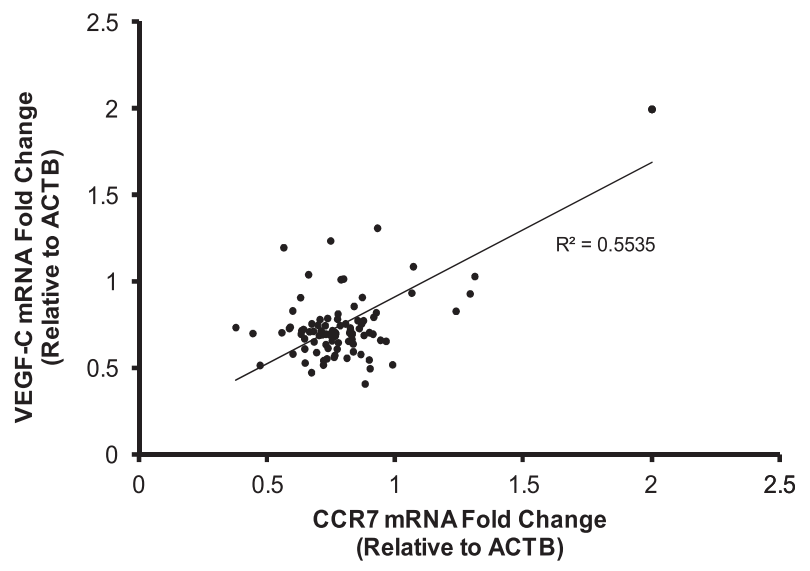

Figure 5 CCL21/CCR7 pair correlates with lymphangiogenic markers in a panel of breast cancer tissues. (A) Quantitative real-time PCR analysis of CCL21, CCR7 and VEGF-C mRNA expression in control (adjacent non-tumor) and tumoral tissues. Data are represented as a mean \pm SD. $\left(^{*}\right)$ indicates significant differences $(p<0.05)$. (B), (C), (D) mRNA expression level of CCR7 is positively correlated with the expression of lymphatic vascular markers (LYVE1, Podoplanin, VEGF-C) in primary breast cancer samples; Pearson's coefficient indicates strong correlations. (E) mRNA expression level of CCR7 and blood vessel marker CD31 in primary breast cancer samples. Pearson's coefficient suggests little to no correlation between the two variables. Data represent mean values from three independent experiments.

\section{Methods}

\section{Ethics statements}

Human breast cancer specimens and the adjacent nontumor tissues used in this study were obtained from the
Ontario Institute for Cancer Research (OICR) repository (Ontario Tumor Bank) following approval by their Ethics Board. The experimental protocol involving animals was approved by the Animal Use Subcommittee of 
(A)
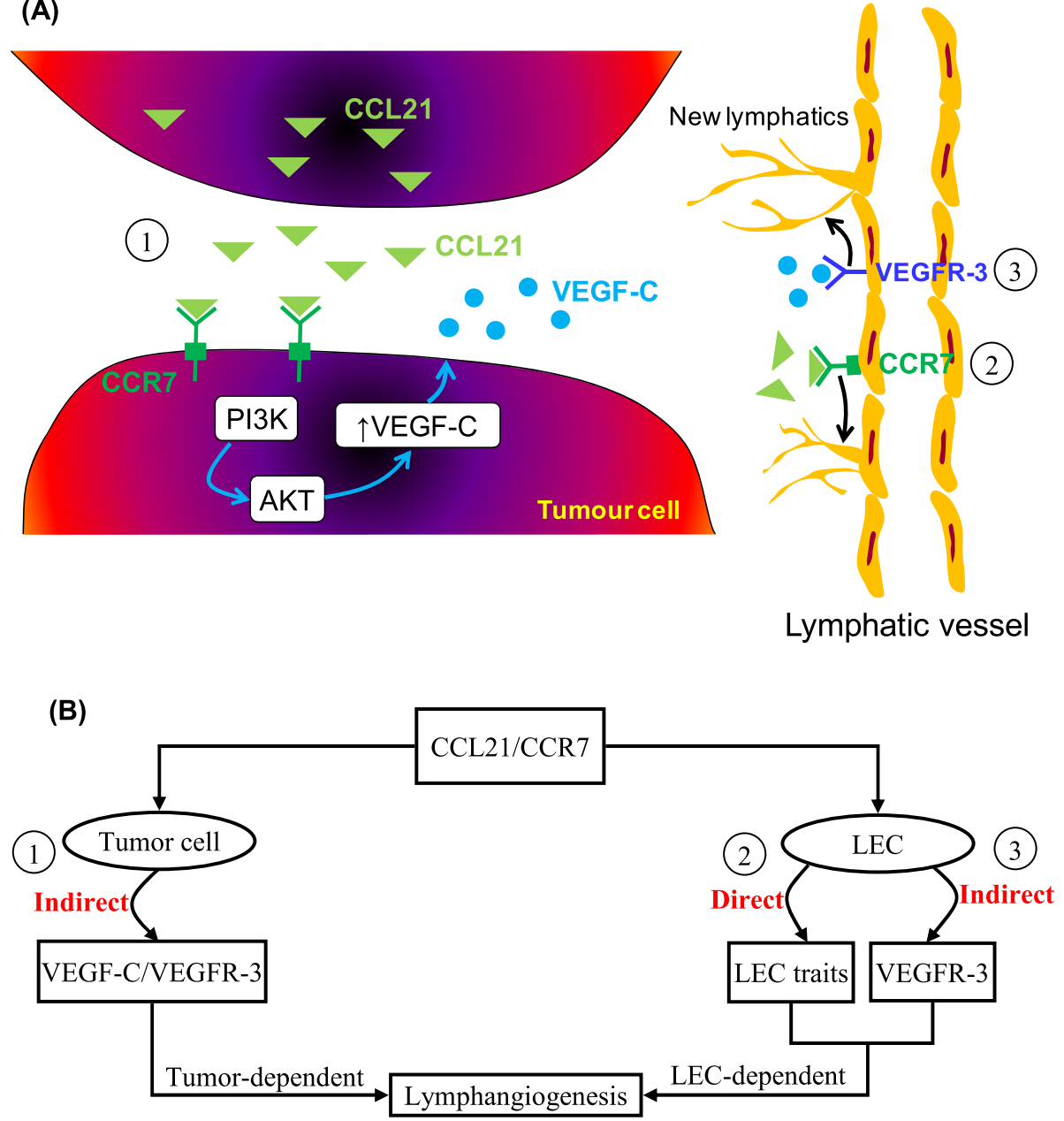

Figure 6 Schematic diagram of the proposed role of CCL21/CCR7 axis in lymphangiogenesis. (A, B) Molecular crosstalk between tumor cells and LECs. 1) Tumor cells enhance the expression of VEGF-C in response to CCL21/CCR7 signaling and promote sprouting of new lymphatics. 2) CCR7-expressing LECs have a direct lymphangiogenic potential by stimulating the pro-lymphangiogenic traits of LECs. 3) LECS respond to CCL21/CCR7 axis through the modulation of VEGFR-3 signaling pathway.

Western University, according to the guidelines of the Canadian Council on Animal Care.

\section{Human tissue samples}

Frozen human breast cancer tissues $(n=105)$ were collected from the primary tumor site with a majority being classified as invasive mammary carcinomas. Control tissues $(n=20)$ were obtained from adjacent non-tumor tissue from unrelated patients and subjected to histopathological analysis to confirm their status. Analyzed samples included variable amounts of duct, stroma and adipose tissue. A summary of demographic, estrogen receptor (ER), progesterone receptor (PR), and human epidermal growth factor receptor-2 (HER-2) status for patient and control populations is presented in Additional file 3: Table S1. The majority of the cancer patients $(>80 \%$, data not provided) had a history of some unspecified cancer in the family. Of the tumor tissues, $76 \%$ were ER positive, 62.9\% PR positive, 20\% HER2 positive, and 9.5\% triple (ER/PR/HER2) negative.

\section{Cell lines and culture}

Primary Adult Human Dermal Lymphatic Microvascular Endothelial Cells (HMVEC-dLyAd) were obtained from Clonetics ${ }^{\circledast} /$ Lonza (Walkersville, MD, USA). The initial expansion and subsequent passages (maximum of 5) were performed according to the manufacturer's instructions. Human MDA-MB-231 and MCF-7 breast cancer cell lines from American Type Culture Collection (ATCC) (Rockville, MD, USA) were grown in a humidified incubator at $37^{\circ} \mathrm{C}$ with $5 \% \mathrm{CO}_{2}$ and maintained as per instructions.

\section{Gene knockdown/knockin and stable transfection}

MDA-MB-231 cells $\left(10^{6}\right.$ cells $\left./ \mathrm{ml}\right)$, were transfected with either silencer small hairpin interfering RNA (shRNA) 
targeting CCR7 (Gene ID: 1236, TF314124, OriGene Technologies, Rockville, MD, USA) or silencer negative control shRNA (TR30015, OriGene Technologies) constructs using the Amaxa Cell Line Nucleofector Kit (Lonza, Walkersville, MD, USA). MCF-7 cells $\left(3 \times 10^{6}\right.$ cells $/ \mathrm{ml}$ ) were transfected with either GFP-tagged ORF clone of CCL21 (Gene ID: NM_002989, RC206579, OriGene Technologies) or control plasmid vector (pCMV6-C) (PS100010, OriGene Technologies). For stable selection, Puromycin $(300 \mathrm{ng} / \mathrm{ml})$ and Geneticin (400 ng/ml) were used on MDA-MB-231 and MCF7 cells, respectively. The nucleofection efficiency was determined with quantitative real-time PCR and Western blot.

\section{RNA extraction, CDNA synthesis, and reverse transcriptase} polymerase chain reaction (RT-PCR)

Total RNA was extracted using the RNeasy Minikit (Qiagen, Valencia, MD, USA) following manufacturer's instructions. cDNA was synthesized with a High Capacity cDNA Reverse Transcription kit (Applied Biosystems, Carlsbad, CA, USA) using up to $2 \mu \mathrm{g}$ of RNA. Primers for the human CCR7, CCL21, VEGF-C, and housekeeping gene (GAPDH) were synthesised at the Oligo Factory (London, ON, Canada) (Additional file 4: Table S2). PCR was performed with Platinum PCR SuperMix High Fidelity (Invitrogen, Burlington, ON, Canada). Real-time PCR products were visualized by GelRed Nucleic Acid Gel Stain (Biotium, Hayward, CA, USA) using a gel imaging system (Gel Doc ${ }^{\text {Tix }}$ XR System, Bio-Rad, Mississauga, ON, Canada).

\section{RNA extraction from human breast tissue}

In order to obtain optimal RNA yield and purity, tissues were initially cut with sterile surgical blades to remove the surrounding fat. Following fat removal, the product was weighted to not exceed $30 \mathrm{mg}$ and further subjected to disruption and uniformization with rotor-stator homogenizer (flash sonication for 5 seconds $\times 5$ times) to ensure the appropriate release of RNA as well as the reduction of lysate viscosity. Then, samples were subjected to RNeasy Minikit protocol (Qiagen).

\section{Quantitative real-time PCR}

Reaction was performed in single micro capillary tubes on a LightCycler (Roche Diagnostic, Laval, QC, Canada) with TaqMan ${ }^{\circ}$ Universal PCR Master Mix (Applied Biosystems, Foster City, CA, USA) for control and target gene expression primer probes (TaqMan ${ }^{\circ}$ Gene Expression Assay, Applied Biosystems) (Additional file 5: Table S3). Delta-delta $\mathrm{Ct}(\Delta \Delta \mathrm{Ct})$ method was employed to determine the fold difference $\left(2^{-\Delta \Delta \mathrm{Ct}}\right)$ (Applied Biosystems).

\section{Western blot}

To prepare protein lysates, cells were treated with M-PER Mammalian Protein Extraction Reagent (Thermo Scientific, Rockford, IL, USA) supplemented with HALT Protease Inhibitor Cocktail (Thermo Scientific) and Phosphatase Inhibitor Cocktail (Thermo Scientific). Fifteen micrograms of total protein were electrophoresed per well on a SDSpolyacrylamide gel and transferred onto Immobilon-FL PVDF membranes (Millipore, Billerica, MA, USA). Membranes were then incubated with primary antibodies (Additional file 6: Table S4) and probed with a mixture of IRDye polyclonal secondary antibodies (LICOR Biosciences, Lincoln, NE, USA). Images were read with an Odyssey infrared imaging system (LI-COR Biosciences) and the average density of each band was measured with ImageJ software (National Institutes of Health, Bethesda, MD, USA).

\section{Enzyme-linked immunosorbent assay (ELISA)}

Control and CCR7 shRNA MDA-MB-231 cells were cultured in serum-free media and treated with or without human CCL21/6Ckine (350 ng/ml, R\&D Systems, Minneapolis, MN, USA) for 24 hours before supernatants were collected. Then, VEGF-C concentration in conditioned media was measured by ELISA (Quantikine Human VEGF-C Immunoassay, R\&D Systems). For signaling studies, cells were pretreated with various concentrations of PI3 kinase inhibitor (LY294002) (Cell Signalling Technology, Danvers, MA, USA), AKT inhibitor (Akti-1/2) (Abcam, Cambridge, MA, USA), and MEK 1/2 inhibitor (U0126) (Cell Signalling). Tumor cells were then treated with CCL21/6Ckine for 24 hours and the level of VEGF-C secretion was determined. In order to quantify CCL21 protein secretion, MDA-MB-231 and HMVEC-dLy cells were maintained in 2D and 2D-matrix culture conditions and subjected to Quantikine Human 6Ckine Immunoassay (R\&D Systems).

\section{Functional assays \\ Proliferation}

Serum-starved HMVEC-dLy cells were seeded onto 96-well tissue-culture microplates, treated with various concentrations of CCL21/6Ckine $(0,100,200$, and $350 \mathrm{ng} / \mathrm{ml}$ ) for 24 hours, and a cell proliferation ELISA BrdU (colorimetric) assay (Roche Applied Science, Indianapolis, IN, USA) was performed.

\section{Migration}

Cellular migration was assessed with Boyden chambers using Transwell ${ }^{\circ}$ inserts (Corning Life Sciences, Oneonta, NY, USA) separated by a polycarbonate membrane with $8 \mu \mathrm{m}$ pore opening placed within 24-well plates. A two hundred microliter suspension of serum-starved HMVEC-dLy cells at a concentration of $2 \times 10^{5} / \mathrm{ml}$ were 
seeded in the upper chamber while various concentrations of CCL21/6Ckine $(0,100,200$, and $350 \mathrm{ng} / \mathrm{ml})$ were added to serum-free media in the lower chamber. The assembled chambers were then incubated for 24 hours. After incubation, the cells from the top of the membrane were wiped off with cotton swabs whereas the migrated cells (from the bottom of the membrane) were fixed with cold methanol, stained with eosin/thiazine, and washed with distilled water. The membranes were then dried, cut with surgical blade, and fixed with mounting medium on a glass slide. Direct microscopic counting at $40 \times$ magnification (Leica DFC 295, Leica Microsystems, Germany) of cells that have migrated to the lower side of the membrane was performed and a mean value for each sample was calculated.

\section{Tube formation}

HMVEC-dLy grown up in T75 flasks to near confluence (80\%) were trypsinized and resuspended in endothelial basal media (EBM) (without any growth supplements) to a final concentration of $2 \times 10^{5}$ cells $/ \mathrm{ml}$. Growth Factor Reduced Matrigel (BD Biosciences, Mississauga, ON, Canada) was thawed overnight at $4^{\circ} \mathrm{C}$, diluted with cold EBM (1:1 dilution) and then a volume of $300 \mu \mathrm{l}$ Matrigel solution/well was placed in six-well plates to solidify for 2 hours. After that, HMVEC-dLy cells $(2 \mathrm{ml}$ of cell suspension) were seeded on the solidified Matrigel under various concentrations of CCL21/6Ckine $(0,100,200$, and $350 \mathrm{ng} / \mathrm{ml}$ ) for 24 hours. Tube formation was examined on an inverted microscope (100x magnification) at different time intervals. Images were randomly taken with Leica EC3 camera (Leica Microsystems) in different areas of the wells by selecting fields of view that were distinct and distant enough to not overlap with each other. The total length of the interconnected cells forming tubular structures was measured with ImageJ.

\section{Directed in vivo lymphangiogenesis assay}

To study the loss of function, the highly aggressive MDA-MB-231 breast cancer cell line that expresses high endogenous levels of VEGF-C was used after CCR7 knockdown. To study the gain-of-function, the poorly aggressive MCF-7 breast cancer cell line that expresses low endogenous VEGF-C was used after CCL21 knockin. Four angioreactors (Trevigen, Gaithersburg, MD, USA) with identical conditions/mouse $\left(4 \times 10^{4}\right.$ cells/angioreactor) were implanted into the dorsal flank of 6-to 8-week-old female nude mice (4 mice/condition) (Hsd.Athymic Nude-Foxn $1^{n u} /$ Foxn $1^{+}$, Indianapolis, IN, USA) and the assay was carried out as previously described [43]. Three different approaches were employed for this purpose:

\section{Spectrofluorimetry}

To quantify lymphatic ingrowths, angioreactors were removed from surrounding tissues and cellular contents were retrieved. The fluorescence signal of Lyve-1, Prox-1, and CD31 markers (Additional file 6: Table S4) was measured with a FLUOstar Omega (Fisher Scientific, San Jose, CA, USA) spectrofluorimeter (excitation $584 \mathrm{~nm}$, emission $620 \mathrm{~nm}$ ).

\section{Quantitative real-time $P C R$}

To assess the expression of lymphangiogenic markers in the cellular contents of angioreactors, total mRNA was extracted and quantitative PCR was performed with specific murine probes (Additional file 5: Table S3).

\section{Immunofluorescence staining}

It was carried out in serial frozen sections of angioreactors as previously described $[34,43]$ using appropriate antibodies (Additional file 6: Table S4). Representative images were taken with a LSM 510 META confocal microscope (Carl Zeiss Microscopy, Jena, Germany) and micro (blood) and lymphatic vessel densities (MVD/ LVD) were assessed in dual immunostained sections as reported in the past [34].

\section{Statistical analysis}

Statistical calculations were performed using GraphPad Prism software version 5 (GraphPad Software, La Jolla, CA, USA). All parametric data were analyzed with one-way ANOVA followed by Tukey-Kramer or Dunnett post-hoc comparisons. Student's $t$-test was used when comparing two datasets and Pearson's coefficient was employed to assess statistical correlations. Statistically relevant differences between means were accepted at $\mathrm{p}<0.05$.

\section{Additional files}

Additional file 1: Figure S1. $(A)$ Western blot and (B) real-time $P C R$ analysis of CCR7, CCL21, and VEGF-C expression in T47D, MCF-7, Hs578t, and MDA-MB-231 breast cancer cell lines. GAPDH was used as an internal control. (C) CCL21 protein secretion by MDA-MB-231 as measured by ELISA in 2D and 2D-matrix conditions. Data are represented as mean \pm SD $(n=3) .\left(^{*}\right)$ indicates statistical significant differences $(p<0.005)$

Additional file 2: Figure S2. (A) Immunofluorescence staining depicts the expression of CCR7. Green (Alexa fluor labeling) represents CCR7 protein expression and blue (DAPI) represents nuclei. Images were taken under 40x magnification. (B) Quantitative PCR of CCR7 mRNA expression in LECs obtained from angioreactors subject to different treatment conditions. Data is presented relative to growth factor-reduced basement membrane extract (BME) alone. Data are represented as mean \pm SD $(n=3)$. $\left(^{*}\right)$ indicates statistical significant differences $(p<0.005)$. (C) Immunofluorescence staining of the lymphangiogenic marker Prox-1 showing its nuclear localization in LECs. Image was taken under 40x magnification.

Additional file 3: Table S1. Demographic details and tumor characterization.

Additional file 4: Table S2. Primers information for real-time PCR. 
Additional file 5: Table S3. Primer probe information for quantitative real-time $P C R$.

Additional file 6: Table S4. Antibodies for Western blot,

immunofluorescence and immunohistochemical analyses.

\section{Abbreviations}

ACTB: Actin, beta; ANOVA: Analysis of variance; CCL21/6Ckine: C-C chemokine ligand 21; CCR7: C-C chemokine receptor 7; CD31: Cluster of differentiation 31; COX-2: Cyclooxygenase 2; DAPI: 4', 6-diamidino-2-phenylindole; DIVLA: Directed in vivo lymphangiogenic assay; DNA: Deoxyribonucleic acid; ELISA: Enzyme-linked immunosorbent assay; EP1: EP4, Prostanoid receptor 1, 4; ERK1/2: Extracellular regulated kinase 1/2; GAPDH: Glyceraldehyde 3-phosphate dehydrogenase; HMVEC-dLyAd: Primary adult human dermal lymphatic microvascular endothelial cells; LVD: Lymphatic vessel densities; LYVE-1: Lymphatic vessel endothelial receptor-1; LECs: Lymphatic endothelial cells; MVD: Micro vessel densities; PI3K: Phosphatidylinositol 3-kinase; PROX-1: Prospero homebox protein-1; PKB/AKT: Protein kinase B; PGE2: Prostaglandin E2; RT-PCR: Reverse transcriptase polymerase chain reaction; VEGF-C: Vascular endothelial growth factor-C; VEGFR-3: Vascular endothelial growth factor receptor-3.

\section{Competing interests}

The authors declare that they have no competing interests.

\section{Authors' contributions}

ETF conceived and designed the study, performed data acquisition and interpretation for Figures 1, 2, 3, 5, 6 and partially for Figure 4, and wrote and revised the manuscript. MM performed the experiments for Subfigure $4 B, S 2 B$, S2C, and revised the manuscript. XX performed the immunohistochemistry experiments. PKL supervised the study and revised the manuscript. All authors read and approved the final manuscript.

\section{Acknowledgements}

The authors thank Dr. Girish Gannareddy for his help with animal work. This study was supported by grants from the Canadian Breast Cancer Foundation, Ontario Chapter and the Ontario Institute of Cancer Research to PKL. ETF and MM were supported in part through funding provided by Canadian Institutes of Health Research Strategic Training Program in Cancer Research and Technology Transfer (CIHR-CaRTT), and Pamela Greenaway-Kohlmeier Translational Breast Cancer Research Unit (TBCRU).

\section{Author details}

${ }^{1}$ Department of Anatomy \& Cell Biology, Schulich School of Medicine and Dentistry, Western University, 1151 Richmond St, London, ON N6A 5C1, Canada. ${ }^{2}$ Department of Oncology, Schulich School of Medicine and Dentistry, Western University, 790 Commissioners Rd. E, London, ON N6A 4L6, Canada. ${ }^{3}$ Children's Health Research Institute, 800 Commissioners Rd. E, London, ON N6C 2V5, Canada.

Received: 17 July 2014 Accepted: 27 January 2015

\section{Published online: 10 February 2015}

\section{References}

1. Mantovani A, Bonecchi R, Locati M. Tuning inflammation and immunity by chemokine sequestration: decoys and more. Nat Rev Immunol. 2006;6:907-18,

2. Balkwill F. Cancer and the chemokine network. Nat Rev Cancer. 2004;4:540-50.

3. Keeley EC, Mehrad B, Strieter RM. Chemokines as mediators of neovascularization. Arterioscler Thromb Vasc Biol. 2008;28:1928-36.

4. Ben-Baruch A. Organ selectivity in metastasis: regulation by chemokines and their receptors. Clin Exp Metastasis. 2008;25:345-56.

5. Garin A, Proudfoot AEl. Chemokines as targets for therapy. Exp Cell Res. 2011:317:602-12

6. Mishra P, Banerjee D, Ben-Baruch A. Chemokines at the crossroads of tumor-fibroblast interactions that promote malignancy. J Leukoc Biol. 2010;89:31-9.

7. Muller A, Homey B, Soto H, Ge N, Catron D, Buchanan ME, et al. Involvement of chemokine receptors in breast cancer metastasis. Nature. 2001:410:50-6.

8. Ding Y, Shimada Y, Maeda M, Kawabe A, Kaganoi J, Komoto I, et al. Association of CC chemokine receptor 7 with lymph node metastasis of esophageal squamous cell carcinoma. Clin Cancer Res. 2003;9:3406-12.
9. Takeuchi H, Fujimoto A, Tanaka M, Yamano T, Hsueh E, Hoon DS. CCL21 chemokine regulates chemokine receptor CCR7 bearing malignant melanoma cells. Clin Cancer Res. 2004;10:2351-8.

10. Cabioglu N, Yazici MS, Arun B, Broglio KR, Hortobagyi GN, Price JE, et al. CCR7 and CXCR4 as novel biomarkers predicting axillary lymph node metastasis in T1 breast cancer. Clin Cancer Res. 2005;11:5686-93.

11. Sancho M, Vieira JM, Casalou C, Mesquita M, Pereira T, Cavaco BM, et al. Expression and function of the chemokine receptor CCR7 in thyroid carcinomas. J Endocrinol. 2006;191:229-38.

12. Sun RH, Wang GB, Li J, Cui J. [Role of CCL21/CCR7 in invasion of colorectal carcinoma cell line SW480]. Ai Zheng. 2009;28:708-13.

13. Liu Y, Ji R, Li J, Gu Q, Zhao X, Sun T, et al. Correlation effect of EGFR and CXCR4 and CCR7 chemokine receptors in predicting breast cancer metastasis and prognosis. J Exp Clin Cancer Res. 2010;29:16.

14. Wang J, Seethala RR, Zhang Q, Gooding W, van Waes C, Hasegawa H, et al. Autocrine and paracrine chemokine receptor 7 activation in head and neck cancer: implications for therapy. J Natl Cancer Inst. 2008;100:502-12.

15. Andre F, Cabioglu N, Assi H, Sabourin JC, Delaloge S, Sahin A, et al. Expression of chemokine receptors predicts the site of metastatic relapse in patients with axillary node positive primary breast cancer. Ann Oncol. 2006:17:945-51.

16. Zhao B, Cui $K$, Wang C-L, Wang A-L, Zhang B, Zhou W-Y, et al. The chemotactic interaction between CCL21 and its receptor, CCR7, facilitates the progression of pancreatic cancer via induction of angiogenesis and lymphangiogenesis. Journal of Hepato-Biliary-Pancreatic Sciences 2011;18:821-8

17. Guo J, Lou W, Ji Y, Zhang S. Effect of CCR7, CXCR4 and VEGF-C on the lymph node metastasis of human pancreatic ductal adenocarcinoma. Oncol Lett. 2013:5:1572-8.

18. Shields JD, Emmett MS, Dunn DB, Joory KD, Sage LM, Rigby H, et al. Chemokine-mediated migration of melanoma cells towards lymphatics-a mechanism contributing to metastasis. Oncogene. 2007;26:2997-3005.

19. Shields JD, Fleury ME, Yong C, Tomei AA, Randolph GJ, Swartz MA Autologous chemotaxis as a mechanism of tumor cell homing to lymphatics via interstitial flow and autocrine CCR7 signaling. Cancer Cell. 2007;11:526-38

20. Pan MR, Hou MF, Chang HC, Hung WC. Cyclooxygenase-2 up-regulates CCR7 via EP2/EP4 receptor signaling pathways to enhance lymphatic invasion of breast cancer cells. J Biol Chem. 2008;283:11155-63.

21. Issa A, Le TX, Shoushtari AN, Shields JD, Swartz MA. Vascular endothelial growth factor- $C$ and $C-C$ chemokine receptor 7 in tumor cell-lymphatic cross-talk promote invasive phenotype. Cancer Res. 2009;69:349-57

22. Shields JD, Kourtis IC, Tomei AA, Roberts JM, Swartz MA. Induction of lymphoidlike stroma and immune escape by tumors that express the chemokine CCL21. Science. 2010;328:749-52.

23. Yu M, Tang Z, Alousi S, Berk RS, Miller F, Kosir MA. Expression patterns of lymphangiogenic and angiogenic factors in a model of breast ductal carcinoma in situ. Am J Surg. 2007;194:594-9.

24. Skobe M, Hawighorst $T$, Jackson DG, Prevo R, Janes L, Velasco P, et al. Induction of tumor lymphangiogenesis by VEGF-C promotes breast cancer metastasis. Nat Med. 2001;7:192-8.

25. Mandriota SJ, Jussila L, Jeltsch M, Compagni A, Baetens D, Prevo R, et al. Vascular endothelial growth factor-C-mediated lymphangiogenesis promotes tumour metastasis. EMBO J. 2001;20:672-82.

26. He Y, Rajantie I, Pajusola K, Jeltsch M, Holopainen T, Yla-Herttuala S, et al. Vascular endothelial cell growth factor receptor 3-mediated activation of lymphatic endothelium is crucial for tumor cell entry and spread via lymphatic vessels. Cancer Res. 2005;65:4739-46.

27. Timoshenko AV, Rastogi S, Lala PK. Migration-promoting role of VEGF-C and VEGF-C binding receptors in human breast cancer cells. Br J Cancer. 2007:97:1090-8.

28. Majumder M, Tutunea-Fatan E, Xin X, Rodriguez-Torres M, Torres-Garcia J, Wiebe $R$, et al. Co-expression of alpha9beta1 integrin and VEGF-D confers lymphatic metastatic ability to a human breast cancer cell line MDA-MB468LN. PLoS One. 2012;7:e35094.

29. Rozic JG, Chakraborty C, Lala PK. Cyclooxygenase inhibitors retard murine mammary tumor progression by reducing tumor cell migration, invasiveness and angiogenesis. Int J Cancer. 2001;93:497-506. 
30. Timoshenko AV, Xu G, Chakrabarti S, Lala PK, Chakraborty C. Role of prostaglandin E2 receptors in migration of murine and human breast cancer cells. Exp Cell Res. 2003;289:265-74.

31. Timoshenko AV, Lala PK, Chakraborty C. PGE2-mediated upregulation of iNOS in murine breast cancer cells through the activation of EP4 receptors. Int J Cancer. 2004;108:384-9.

32. Timoshenko AV, Chakraborty C, Wagner GF, Lala PK. COX-2-mediated stimulation of the lymphangiogenic factor VEGF-C in human breast cancer. Br J Cancer. 2006;94:1154-63.

33. Bhattacharjee RN, Timoshenko AV, Cai J, Lala PK. Relationship between cyclooxygenase-2 and human epidermal growth factor receptor 2 in vascular endothelial growth factor C up-regulation and lymphangiogenesis in human breast cancer. Cancer Sci. 2010;101:2026-32.

34. Xin X, Majumder M, Girish GV, Mohindra V, Maruyama T, Lala PK. Targeting COX-2 and EP4 to control tumor growth, angiogenesis, lymphangiogenesis and metastasis to the lungs and lymph nodes in a breast cancer model. Lab Invest. 2012:92:1115-28.

35. Lyons TR, Borges VF, Betts CB, Guo Q, Kapoor P, Martinson HA, et al. Cyclooxygenase-2-dependent lymphangiogenesis promotes nodal metastasis of postpartum breast cancer. J Clin Invest. 2014;124:3901-12.

36. Chuang CW, Pan MR, Hou MF, Hung WC. Cyclooxygenase-2 up-regulates CCR7 expression via AKT-mediated phosphorylation and activation of Sp1 in breast cancer cells. J Cell Physiol. 2013;228:341-8.

37. Wang J, Zhang X, Thomas SM, Grandis JR, Wells A, Chen ZG, et al. Chemokine receptor 7 activates phosphoinositide-3 kinase-mediated invasive and prosurvival pathways in head and neck cancer cells independent of EGFR. Oncogene. 2005:24:5897-904.

38. Liu FY, Zhao ZJ, Li P, Ding X, Zong ZH, Sun CF. Mammalian target of rapamycin (mTOR) is involved in the survival of cells mediated by chemokine receptor 7 through PI3K/Akt in metastatic squamous cell carcinoma of the head and neck. Br J Oral Maxillofac Surg. 2010;48:291-6.

39. Xu Y, Liu L, Qiu X, Jiang L, Huang B, Li H, et al. CCL21/CCR7 promotes G2/M phase progression via the ERK pathway in human non-small cell lung cancer cells. PLoS One. 2011:6:e21119.

40. Xu Y, Liu L, Qiu X, Liu Z, Li H, Li Z, et al. CCL21/CCR7 prevents apoptosis via the ERK pathway in human non-small cell lung cancer cells. PLoS One 2012; 7:e33262.

41. Bruyere F, Noel A. Lymphangiogenesis: in vitro and in vivo models. FASEB J. 2010;24:8-21.

42. Patel S, lozzo RV. Measuring single-cell cytosolic Ca2+ concentration in response to proteoglycans. Methods Mol Biol. 2001;171:435-48.

43. Majumder M, Xin X, Lala PK. A practical and sensitive method of quantitating lymphangiogenesis in vivo. Lab Invest. 2013;93:779-91.

44. Nakamura Y, Yasuoka H, Tsujimoto M, Imabun S, Nakahara M, Nakao K, et al. Lymph vessel density correlates with nodal status, VEGF-C expression, and prognosis in breast cancer. Breast Cancer Res Treat. 2005;91:125-32.

45. Christiansen A, Detmar M. Lymphangiogenesis and cancer. Genes Cancer. 2011;2:1146-58.

46. Lund AW, Swartz MA. Role of lymphatic vessels in tumor immunity: passive conduits or active participants? J Mammary Gland Biol Neoplasia. 2010;15:341-52.

47. Lund AW, Duraes FV, Hirosue S, Raghavan VR, Nembrini C, Thomas SN, et al. VEGF-C promotes immune tolerance in B16 melanomas and cross-presentation of tumor antigen by lymph node lymphatics. Cell Rep. 2012;1:191-9.

48. Swartz MA. Immunomodulatory roles of lymphatic vessels in cancer progression. Cancer Immunol Res. 2014;2:701-7.

49. Worbs T, Forster R. A key role for CCR7 in establishing central and peripheral tolerance. Trends Immunol. 2007:28:274-80.

50. Fang L, Hwang ST. Roles for CCR7 in Cancer Biology. In: Chemokine Receptors in Cancer. 2009. p. 93-108.

51. Karpanen T, Egeblad M, Karkkainen MJ, Kubo H, Yla-Herttuala S, Jaattela M, et al. Vascular endothelial growth factor $\mathrm{C}$ promotes tumor lymphangiogenesis and intralymphatic tumor growth. Cancer Res. 2001;61:1786-90.

52. Norrmen C, Tammela T, Petrova TV, Alitalo K. Biological basis of therapeutic lymphangiogenesis. Circulation. 2011;123:1335-51.

53. Deguchi K, Ichikawa D, Soga K, Watanabe K, Kosuga T, Takeshita H, et al. Clinical significance of vascular endothelial growth factors $C$ and $D$ and chemokine receptor CCR7 in gastric cancer. Anticancer Res. 2010;30:2361-6.

54. Stacker SA, Williams SP, Karnezis T, Shayan R, Fox SB, Achen MG. Lymphangiogenesis and lymphatic vessel remodelling in cancer. Nat Rev Cancer. 2014;14:159-72.
55. Tang $Y$, Zhang D, Fallavollita L, Brodt $P$. Vascular endothelial growth factor $C$ expression and lymph node metastasis are regulated by the type I insulin-like growth factor receptor. Cancer Res. 2003;63:1166-71.

56. Zimmermann N, Conkright JJ, Rothenberg ME. CC chemokine receptor-3 undergoes prolonged ligand-induced internalization. J Biol Chem. 1999:274:12611-8.

57. Nagira M, Imai T, Hieshima K, Kusuda J, Ridanpaa M, Takagi S, et al. Molecular cloning of a novel human CC chemokine secondary lymphoid-tissue chemokine that is a potent chemoattractant for lymphocytes and mapped to chromosome 9p13. J Biol Chem. 1997;272:19518-24

58. Hedrick JA, Zlotnik A. Identification and characterization of a novel beta chemokine containing six conserved cysteines. J Immunol. 1997;159:1589-93.

59. Sironi M, Conti A, Bernasconi S, Fra AM, Pasqualini F, Nebuloni M, et al. Generation and characterization of a mouse lymphatic endothelial cell line. Cell Tissue Res. 2006:325:91-100.

60. Oliveira-Neto HH, de Souza PP, da Silva MR, Mendonca EF, Silva TA, Batista AC. The expression of chemokines CCL19, CCL21 and their receptor CCR7 in oral squamous cell carcinoma and its relevance to cervical lymph node metastasis. Tumour Biol. 2013;34:65-70.

61. Lanati S, Dunn DB, Roussigné M, Emmett MS, Carriere V, Jullien D, et al. Chemotrap-1: an engineered soluble receptor that blocks chemokineinduced migration of metastatic cancer cells in vivo. Cancer Res. 2010;70:8138-48

62. Lin Y, Sharma S, John MS. CCL21 cancer immunotherapy. Cancers. 2014;6:1098-110 (Basel).

63. Baratelli F, Takedatsu H, Hazra S, Peebles K, Luo J, Kurimoto PS, et al. Pre-clinical characterization of GMP grade CCL21-gene modified dendritic cells for application in a phase I trial in non-small cell lung cancer. J Transl Med. 2008:6:38.

\section{Submit your next manuscript to BioMed Central and take full advantage of:}

- Convenient online submission

- Thorough peer review

- No space constraints or color figure charges

- Immediate publication on acceptance

- Inclusion in PubMed, CAS, Scopus and Google Scholar

- Research which is freely available for redistribution

Submit your manuscript at www.biomedcentral.com/submit 